\title{
Whole-Genome Mapping of Stripe Rust Resistance Quantitative Trait Loci and Race Specificity Related to Resistance Reduction in Winter Wheat Cultivar Eltan
}

\author{
Lu Liu, ${ }^{1}$ Meinan Wang, ${ }^{1}$ Junyan Feng, ${ }^{1,2}$ Deven R. See, ${ }^{1,3}$ and Xianming Chen ${ }^{1,3, \dagger}$ \\ ${ }^{1}$ Department of Plant Pathology, Washington State University, Pullman 99164-6430, WA, U.S.A. \\ ${ }^{2}$ Institute of Biotechnology and Nuclear Technology Research, Sichuan Academy of Agricultural Sciences, Chengdu 610061, China \\ ${ }^{3}$ Wheat Health, Genetics and Quality Research Unit, U.S. Department of Agriculture Agricultural Research Service, Pullman 99164-6430, \\ WA, U.S.A. \\ Accepted for publication 4 February 2019.
}

\begin{abstract}
Winter wheat cultivar Eltan has been one of the most widely grown cultivars in the U.S. Pacific Northwest. It has shown variable levels of resistance to stripe rust in different years since it was released in 1990. To map all currently effective and defeated resistance genes in Eltan and understand the factors causing the resistance changes, $112 \mathrm{~F}_{2: 5}$ recombinant inbred lines (RILs) were developed from a cross of Eltan with cultivar Avocet S. The RILs were evaluated in fields of Pullman, Washington in 2015, 2016, 2017, and 2018 and Mount Vernon, Washington in 2016 and 2017 under natural infections; they were also evaluated in the greenhouse with races PSTv-4 and PSTv-40 of Puccinia striiformis f. sp. tritici. The RILs were genotyped with the 90K Illumina iSelect wheat single-nucleotide polymorphism chip. A total of five quantitative trait loci (QTLs) were identified in Eltan. Two major QTLs

on chromosome arms $2 \mathrm{BS}$ and $4 \mathrm{AL}$ were detected in the greenhouse tests, explaining up to 28.0 and $42.0 \%$ of phenotypic variation, respectively. The two race-specific QTLs were also detected in some field experiments but with reduced effects. A minor QTL on 5BS was detected in the greenhouse and field tests, explaining 10.0 to $14.8 \%$ of the phenotypic variation. The other two minor QTLs were mapped on 6AS and 7BL and detected only in field experiments, explaining up to 20.5 and $13.5 \%$ of phenotypic variation, respectively. All stripe rust samples collected in the experimental fields in 2015 and 2016 were identified as P. striiformis f. sp. tritici races virulent on seedlings of Eltan. The resistance reduction of Eltan was caused by changes of the $P$. striiformis f. sp. tritici population from avirulent to virulent, overcoming the race-specific allstage resistance in Eltan.
\end{abstract}

Stripe rust (also called yellow rust), caused by Puccinia striiformis Westend. f. sp. tritici Erikss., is one of the most devastating and economically important diseases across major wheat-growing regions in the world (Wellings 2011). In the United States, this disease was first observed in 1915 (Carleton 1915), and it has caused epidemics in the western United States since the late 1950s. Since the 1980s (especially the year 2000), wheat stripe rust has become increasingly more frequent and caused major damages in the regions east of the Rocky Mountains, making it an important disease throughout the inland United States (Chen et al. 2002; Line and Qayoum 1992). Under favorable conditions for the disease development, stripe rust can cause complete yield losses on susceptible cultivars in the U.S. Pacific Northwest (PNW) (Chen 2005). Based on experimental data, the long-term average yield loss

${ }^{\dagger}$ Corresponding author: X. Chen; xianming.chen@ars.usda.gov

Funding: This research was supported by U.S. Department of Agriculture Agricultural Research Service project 2090-22000-018-00D; Vogel Foundation project 13Z-3061-6665; Washington Grain Commission project 13C-3061-5665; and Washington State University, Department of Plant Pathology, College of Agricultural, Human, and Natural Resource Sciences, Agricultural Research Center HATCH project WNP00461.

Mention of trade names or commercial products in this publication is solely for the purpose of providing specific information and does not imply recommendation or endorsement by the U.S. Department of Agriculture (USDA). The USDA is an equal opportunity provider and employer.

*The $\boldsymbol{e}$-Xtra logo stands for "electronic extra" and indicates that three supplementary tables are published online.

The author(s) declare no conflict of interest.

This article is in the public domain and not copyrightable. It may be freely reprinted with customary crediting of the source. The American Phytopathological Society, 2019. from 1975 to 2001 was $36 \%$ for susceptible winter wheat and $27 \%$ for susceptible spring wheat cultivars (Sharma-Poudyal and Chen 2011). However, the estimated average yield losses increased to 43.7 and $20.7 \%$ on susceptible winter and spring wheat varieties, respectively, for the period from 2002 to 2017 (Chen 2014; Chen et al. 2015, 2016, 2017, 2018). Although stripe rust resistance in wheat cultivars commercially grown during the same period was able to reduce potential yield losses to an average of $8.5 \%$, chemical control to further reduce yield losses cost growers multimillions of dollars.

Epidemics of stripe rust usually occur with new virulent races and favorable weather conditions (Chen 2005; Wan et al. 2004). The long-distance migration, high rate of mutation, somatic recombination, and cultivar selection contribute to the constant change of P. striiformis f. sp. tritici populations (Chen 2005; Hovmøller and Justesen 2007; Lei et al. 2017). In the PNW, new races have been identified every year, and race composition is more diverse than in any other regions of the United States (Wan and Chen 2012, 2014; Wan et al. 2016). Traditionally, wheat breeders have selected breeding lines with strong all-stage resistance (ASR), which is usually controlled by a major gene and easy to incorporate into new cultivars. However, ASR is mostly race specific and can be easily overcome by new virulent races. If cultivars with race-specific ASR are widely grown, new virulent races may become widespread and cause large-scale epidemics. This was the case for the stripe rust epidemics in the United States in the early 2000s when races virulent to $\operatorname{Yr} 9$ occurred in high frequency (Chen 2005, 2007; Chen et al. 2002, 2010). In contrast to ASR, adult plant resistance (APR) and high-temperature adult plant (HTAP) resistance to stripe rust are often nonrace specific and therefore, durable. However, APR and HTAP resistance are usually controlled by minor effect genes, and they are relatively difficult to incorporate into new cultivars. Also, because of the partial resistance and influences by temperature, 
plant growth stage, and disease pressure, APR and HTAP resistance may not provide adequate control (Chen 2005, 2013, 2014). For example, the cloned APR genes Yr18 (Krattinger et al. 2009) and Yr46 (Moore et al. 2015) and the HTAP resistance gene Yr36 (Fu et al. 2009; Gou et al. 2015) are all nonrace specific and provide partial resistance. The best strategy is to combine several genes for effective ASR with APR or HTAP resistance to achieve high-level and durable resistance (Chen 2007, 2013, 2014).

Winter wheat cultivar Eltan (PI 536994) was developed from the cross Luke//BR-70443-4 (PI 167822/CI 013438) and released in 1990 (Peterson et al. 1991). Eltan was the most widely grown cultivar in the PNW from the late 1990s to the early 2000s. For example, Eltan was grown on $22.8 \%$ of winter wheat acreage in the state of Washington during the period of 2002 to 2012 (Chen 2014). Because of its wide adaptation in low- and intermediate-rainfall areas, Eltan has been one of the most important elite cultivars used in winter wheat breeding programs in the PNW. At the time of release, Eltan was moderately susceptible to some $P$. striiformis $\mathrm{f}$. sp. tritici races but resistant to snow mold, common bunt, and dwarf bunt (Peterson et al. 1991). In field tests at various locations in the state of Washington, Eltan was highly resistant (mostly infection type $[\mathrm{IT}]=0$ to 3 and severity 0 to $10 \%$; occasionally, IT $=5$ to 8 and severity up to $50 \%$ ) from 1999 to 2009 . It had more frequent IT $=5$ and severity readings in the range of 30 to $50 \%$ from 2010 to 2015 . It has become more susceptible, with IT $=7$ to 8 and severity in the range of 30 to $60 \%$ in more locations since 2016; these values were still much lower than the severity values of 90 to $100 \%$ of the susceptible checks (Chen et al. 2015, 2016, 2017, 2018) (X. M. Chen, unpublished data). Based on greenhouse tests, Eltan has both race-specific ASR and nonrace-specific HTAP resistance. The level of HTAP resistance seemed lower to the predominant races (with mostly IT =5) in the tests from 2012 to 2018 than those from 2000 to 2011 (X. M. Chen, unpublished data). The Eltan resistance to stripe rust has become less effective in the last 20 years. However, the genes for stripe rust resistance in Eltan were not known, and it was not clear which genes are still effective and which are not. Therefore, this study was conducted to further characterize the stripe rust resistance in Eltan, determine the genetics of resistance, map all possible effective and defeated genes, and determine the factors causing the resistance changes in this important wheat cultivar. The information obtained in this study should be useful for breeding new wheat cultivars with durable, high-level resistance to stripe rust.

\section{MATERIALS AND METHODS}

Plant materials. Susceptible spring wheat cultivar Avocet $S$ $(\mathrm{AvS})$, Eltan, and $112 \mathrm{~F}_{2: 5}$ recombinant inbred lines (RILs) of $\mathrm{AvS} \times$ Eltan developed through single-seed decent were used for the tests for stripe rust phenotypes in the greenhouse and fields and DNA extraction for marker genotyping.

Characterization of stripe rust resistance in Eltan. Seedlings and adult plants of Eltan were tested in the greenhouse at both low- and high-temperature (HT) profiles as described in a four-way test (seedling: low temperature [LT], seedling: HT, adult: LT, and adult: HT) by Chen (2013). Five P. striiformis f. sp. tritici races were used in the test, including PSTV-4 (isolate 13-445), PSTv-14 (12-116), PSTv-37 (12-114), and PSTv-40 (09-78), which have been predominant races since 2000, and PSTv-18 (11-2812G), which was the predominant race in the 1990s (Liu et al. 2017; Wan and Chen 2014). For seedling tests, six plants each of AvS and Eltan at the two-leaf stage were uniformly dust inoculated with a mixture of urediniospores of a specific race and talc at a ratio of 1:20 (Chen and Line 1992). Inoculated plants were kept in a dew chamber at $10^{\circ} \mathrm{C}$ for $24 \mathrm{~h}$ without light and then placed into two separate growth chambers: one with an LT diurnal cycle $\left(4\right.$ to $\left.20^{\circ} \mathrm{C}\right)$, and the other with an HT diurnal cycle $\left(10\right.$ to $\left.30^{\circ} \mathrm{C}\right)$; both had a 16-h light/8-h dark photoperiod (Chen 2013; Chen and Line 1995). For adult plant tests, three plants each of AvS and Eltan were used for each race and each temperature profile. Flag leaves were dust inoculated, and plants were tested in the same conditions as described above. IT was recorded for each plant 18 to 20 days after inoculation based on a 0 to 9 scale (Line and Qayoum 1992).

Evaluating RILs for stripe rust reaction in the greenhouse. Races PSTv-4 and PSTV-40 were used for testing the RIL population in the greenhouse, because Eltan showed resistance and moderate resistance to the two races, respectively; by contrast, AvS was susceptible to both races. Around 15 plants of each RIL at the two-leaf stage were tested at LT $\left(4\right.$ to $\left.20^{\circ} \mathrm{C}\right)$. The inoculation method and test conditions were the same as in the seedling test described above. To identify HTAP resistance quantitative trait loci (QTLs), three plants for each RIL at the heading stage were tested with PSTV-4 at HT (10 to $\left.30^{\circ} \mathrm{C}\right)$. The inoculation method and test conditions were the same as in the adult plant test described above. The parents AvS and Eltan were included in each test.

Evaluating RILs for stripe rust reaction in fields. The parents and $\mathrm{F}_{2: 5}$ RILs were planted in the fields of Pullman (eastern Washington) and Mount Vernon (western Washington) in October 2014. The two locations are $\sim 500 \mathrm{~km}$ apart and have different P. striiformis f. sp. tritici race composition as well as different weather conditions. The wheat lines were arranged in a randomized block design with three replications. Each replication consisted of one row of each $\mathrm{F}_{2: 5}$ RIL and both parents, with the susceptible check PS279 included every 20 rows. Approximately 30 seeds of each $\mathrm{F}_{2: 5}$ line were planted in a $50-\mathrm{cm}$ row and spaced $20 \mathrm{~cm}$ apart in October 2014. The fields were managed with fertilizers and herbicides in the practice typical for each region. Stripe rust IT and disease severity (DS) data were recorded three times at late jointingbooting (Zadoks 39 to 45), heading-flowering (Zadoks 50 to 60), and milk-soft dough (Zadoks 75 to 85) stages (Zadoks et al. 1974) in June and July 2015 as previously described (Liu et al. 2018). DS data were used to calculate the area under the disease progress curve (AUDPC) (Chen and Line 1995), which was then converted to the relative area under the disease progress curve (rAUDPC) as the percentage of the AUDPC of the susceptible parent AvS (treated as $100 \%$ rAUDPC). The experiment was repeated in the 2015 to 2016 growing season the same way as in the previous year. An $\mathrm{F}_{2: 6}$ RIL population was obtained by harvesting seeds from a single $\mathrm{F}_{2: 5}$ plant for each line grown in the greenhouse for both DNA extraction and generation advancement. The $\mathrm{F}_{2: 6}$ RILs and the parents were evaluated at both Pullman and Mount Vernon locations in the 2016 to 2017 crop season with three replications in each location. From the $\mathrm{F}_{2: 6}$ plants grown in the Pullman location, a single head for each line was randomly harvested to obtain seeds of the $\mathrm{F}_{2: 7}$ generation. In the 2017 to 2018 growth season, $F_{2: 7}$ RILs and parents were evaluated at Pullman without replications.

Statistical analyses of the phenotypic data. Analyses of variance (ANOVA) were performed for the rAUDPC and IT data using the "aov" function in R 3.5.1 (R Foundation for Statistical Computing, Vienna, Austria; http://www.R-project.org/) to determine the effects of genetic and environmental factors and their interaction. Broad-sense heritabilities $\left(H^{2}\right)$ of phenotypic traits were calculated using the formula

$$
H^{2}=\sigma_{G}^{2} /\left[\left(\sigma_{G}^{2}+\sigma_{G E}^{2} / e\right)+\sigma_{E}^{2} /(e \times r)\right]
$$

where $\sigma_{G}^{2}, \sigma_{G E}^{2}$, and $\sigma_{E}^{2}$ were genetic, genetic $\times$ environment, and error variances, respectively, whereas $e$ and $r$ represented the numbers of environments and replications, respectively ( $\mathrm{Lu}$ et al. 2014). ANOVA and $H^{2}$ calculation were performed using the 2015 , 2016, and 2017 field data, whereas the greenhouse tests and 2018 field experiment were not used in these analyses, because no replications were available. Pearson's correlation coefficients of pairwise environments were calculated using both IT and rAUDPC data. Because the RILs were developed from a spring by winter 
wheat cross, spring and winter wheat lines were compared for their reactions to stripe rust using Student $t$ tests to determine whether the growth habits would affect stripe rust reactions.

Evaluating stripe rust samples for virulence. Ten leaf samples bearing stripe rust uredinia were randomly collected from RILs in both Pullman and Mount Vernon in 2015 and 2016. For each sample, urediniospores from one pustule were transferred onto AvS seedlings using a paint brush. Inoculated plants were kept in a dew chamber at $10^{\circ} \mathrm{C}$ for $24 \mathrm{~h}$ without light and then transferred to a growth chamber at the LT profile as described above. Urediniospores were collected 16 to 20 days after inoculation and used to inoculate seedlings of the $Y r$ single-gene differentials: $Y r 1, \operatorname{Yr} 5$, Yr6, Yr7, Yr8, Yr9, Yr10, Yr15, Yr17, Yr24, Yr27, Yr32, Yr43, Yr44, YrSP, YrTr1, YrExp2, and Yr76 (Wan and Chen 2014; Wan et al. 2016). The inoculation method and test conditions were the same as in the seedling tests at LT for Eltan as described above. IT data recorded 18 to 20 days after inoculation were used to obtain a formula of avirulent (IT $=0$ to 6 ) and virulent (IT $=7$ to 9 ) reactions on the set of differentials to identify the race for each stripe rust sample using a previously described method (Wan and Chen 2014; Wan et al. 2016). Eltan was included in the seedling tests to determine if it is resistant or susceptible to each of the stripe rust samples.

DNA extraction and molecular marker genotyping. Seedling leaves were collected from one single plant of each $F_{2: 5}$ RIL, AvS, and Eltan at two-leaf stage, and genomic DNA was extracted from each sample using the CTAB method (Clarke 2002). Quality and quantity of DNA were determined using $0.8 \%$ agarose gel electrophoresis and a spectrophotometer (NanoDrop ND-1000; Thermo Scientific, Wilmington, DE), respectively.
AvS, Eltan, and 112 RILs were genotyped using the $90 \mathrm{~K}(81,587$ markers) Illumina iSelect wheat single-nucleotide polymorphism (SNP) chip (Wang et al. 2014) at the U.S. Department of Agriculture Agricultural Research Service Biosciences Research Laboratory (Fargo, ND). SNP marker calling and clustering were performed using the GenomeStudio v2011.1 software package (Illumina, San Diego, CA), and manual correction was performed when calls were not correctly clustered by the clustering algorithm.

Linkage map construction and QTL analysis. Polymorphic SNP markers with $<10 \%$ missing data were used for linkage map construction using JoinMap 4.1 (Van Ooijen 2006). Additional marker filter was conducted in JoinMap 4.1, including elimination of markers that did not fit a 1:1 segregation ratio at $P>$ 0.01 and treating cosegregating markers as one. The regression mapping algorithm was used to assign linkage groups, and the Kosambi mapping function was used to convert genetic distances to centimorgans. Linkage groups were selected using a minimum logarithm (base 10) of odds (LOD) score of 3.0, and they were assigned to corresponding chromosomes based on the reported chromosomal locations of SNP markers (Wang et al. 2014). Linkage maps were drawn using MapChart v2.3 (Voorrips 2002).

Phenotypic data from nine greenhouse and field tests were used for QTL analysis. The greenhouse data included the IT data of seedling tests at LT with races PSTV-4 (PSTV-4_seedling low temperature [SLT]) and PSTv-40 (PSTv-40_SLT) and the adult plant test at HT with race PSTv-4 (PSTv-4_HTAP). The field data included IT and rAUDPC data of the field tests at Pullman in 2015, 2016, 2017, and 2018 and at Mount Vernon in 2016 and 2017. The data of the Mount Vernon location in 2015 were discarded, because many lines did not have plants owing to the spot flooding problem.
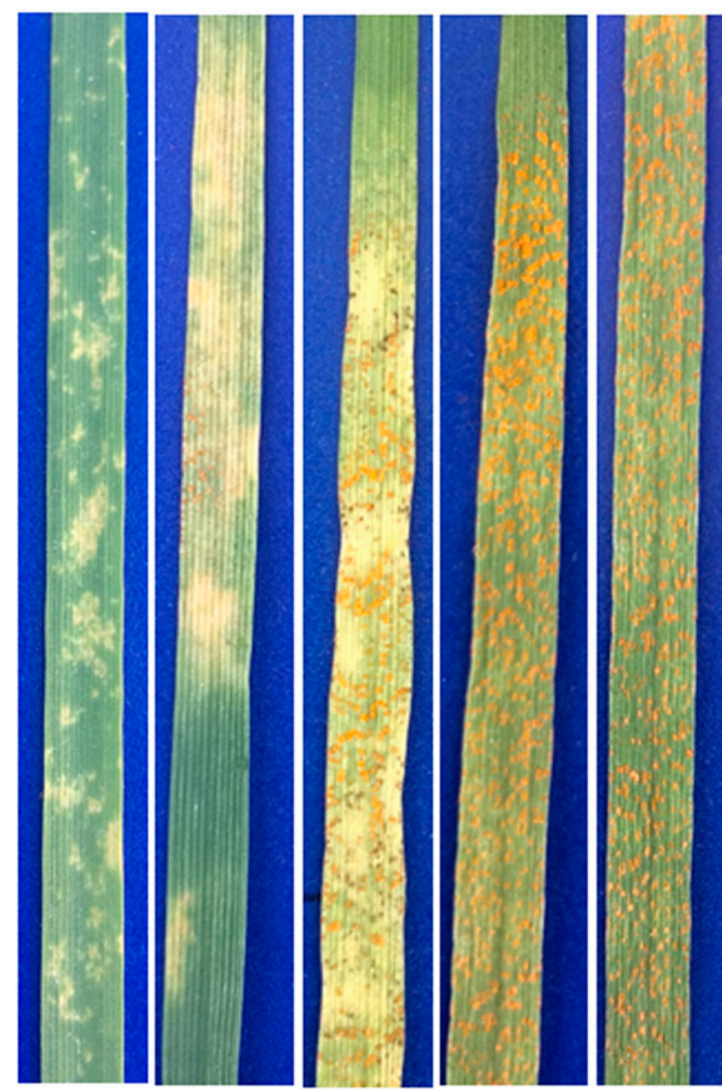

A

B
C
E

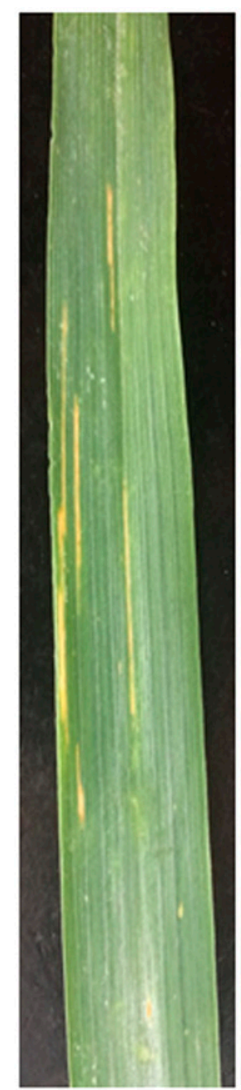

$\mathbf{F}$

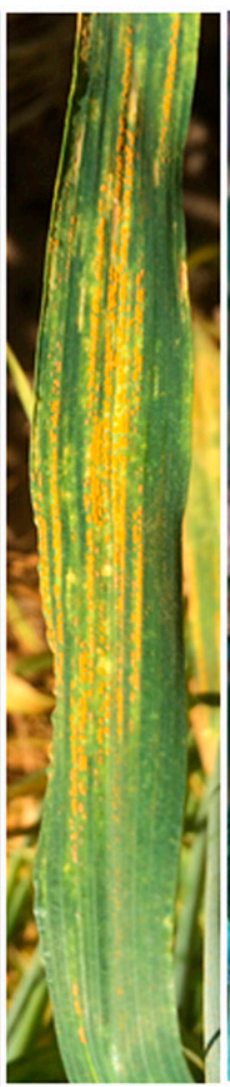

G

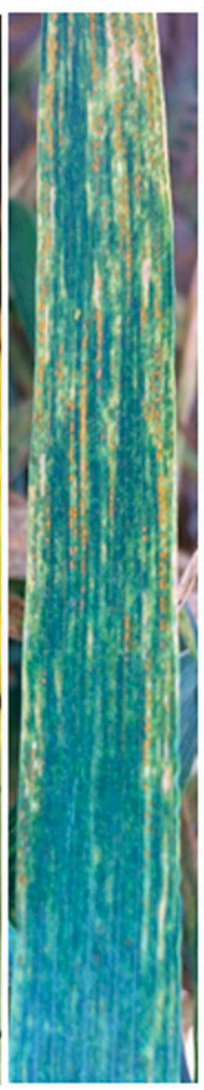

H
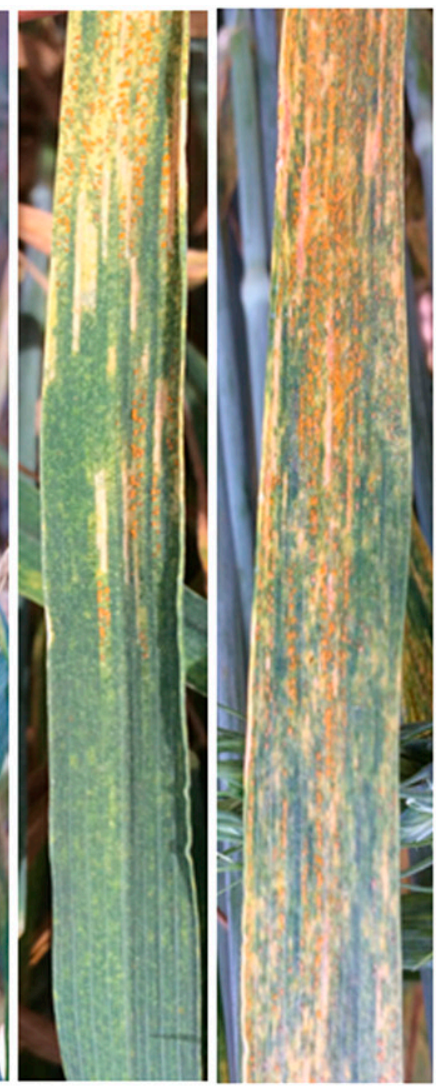

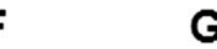

Fig. 1. Stripe rust reactions of cultivar Eltan at seedling stage to races A, PSTv-18, B, PSTv-4, C, PSTv-40, D, PSTv-14, and E, PSTv-37 of Puccinia striiformis f. sp. tritici tested at the low-temperature $\left(4\right.$ to $\left.20^{\circ} \mathrm{C}\right)$ profile and $\mathbf{F}$, the adult plant stage inoculated with PSTv-4 in the greenhouse at the high-temperature (10 to $30^{\circ} \mathrm{C}$ ) profile; they were recorded at the adult plant stage in fields of Pullman in $\mathbf{G}, 2015, \mathbf{H}, 2016, \mathbf{I}, 2017$, and $\mathbf{J}, 2018$ under natural $P$. striiformis f. sp. tritici infection. 
When phenotypic data were recorded multiple times, the highest IT scores recorded were used in QTL analysis. QTL analysis was conducted using the "cim" function for composite interval mapping in the R/QTL 3.5.1 software package (Broman et al. 2003). A significance LOD threshold was calculated for each environment using 1,000 permutations at $P=0.05$ (Churchill and Doerge 1994), and the threshold values ranging from 3.07 to 3.40 were used to declare significant QTLs in different environments. The phenotypic variation and additive effect of each QTL were determined using the "fitqtl" function. No significant interactions between QTLs were observed in any environments.

Amplification of Eltan with markers for stripe rust resistance genes previously mapped to the same chromosomes. To determine the relationships of Eltan QTL with previously reported resistance genes and QTL, sequence-tagged site (STS), simple sequence repeat (SSR), and Kompetitive allele-specific polymerase chain reaction (KASP) markers linked to the previously reported stripe rust resistance genes were tested on AvS and Eltan. These markers included KASP markers $660 \mathrm{~K}-\mathrm{AN} 3,660 \mathrm{~K}-\mathrm{AN} 21,660 \mathrm{~K}$-AN57, and 660K-AN65 for Qyrnap.nwafu-2BS on 2BS (Wu et al. 2017); STS marker Xsun104 for Yr51 (Randhawa et al. 2014) and SSR markers Xwmc219, Xwmc313, and Xwmc776 for Yr60 (Herrera-Foessel et al. 2015) on 4AL; and SSR markers Xgwm234 and Xcfb309 for Yr47 on 5BS (Bansal et al. 2011). KASP assays were conducted following the standard protocols provided by LGC Genomics (https://www.lgcgroup. com/products/kasp-genotyping-chemistry/\#.XCOHBlVKjcs). Winter wheat Luke, which is in the pedigree of Eltan, was also evaluated with the four KASP markers on 2BS. Primers of the STS and SSR markers including the M13 tail were synthesized by Sigma-Aldrich (Atlanta, GA), and polymerase chain reaction (PCR) was conducted using the conditions described by Hou et al. (2015). PCR products were separated on an ABI3730 DNA fragment analyzer (Applied Biosystems, Grand Island, NY) and scored with the software GeneMarker v4.0 (SoftGenetics, LLC, State College, PA). Polymorphic SSR markers were tested on the RIL population and mapped to the linkage groups.

\section{RESULTS}

Stripe rust resistance in Eltan. In the four-way tests, Eltan was resistant at seedling stage to PSTV-4 (IT = 3) and moderately resistant to PSTv-40 (IT = 6), but it was susceptible to PSTv-14 $(\mathrm{IT}=8)$ and PSTv-37 (IT = 8) at LT (Fig. 1). When adult plants were tested at HT, the cultivar had a higher level of resistance to PSTV-4 (IT = 2) and PSTv-40 (IT = 3) and became moderately resistant (IT = 5) to PSTv-14 and PSTv-37 (Table 1). Because both Eltan and AvS were resistant to PSTv-18 at seedling stage, this race was not included in additional analyses. When tested in fields, Eltan plants at heading-flowering stages were moderately resistant (IT $=4$ to 6 ) to susceptible $(\mathrm{IT}=7)$ but with relatively low DS values $(\mathrm{DS}=30$

TABLE 1. Infection types of seedling and adult plants of cultivar Eltan tested with four Puccinia striiformis f. sp. tritici races at the low-temperature (4 to $\left.20^{\circ} \mathrm{C}\right)$ and high-temperature $\left(10\right.$ to $\left.30^{\circ} \mathrm{C}\right)$ profiles $^{\mathrm{a}}$

\begin{tabular}{lccccc}
\hline \multirow{2}{*}{$\begin{array}{l}\text { Growth stage and } \\
\text { temperature }\left({ }^{\circ} \mathrm{C}\right)\end{array}$} & PSTv-4 & PSTv-14 & PSTv-18 & PSTv-37 & PSTv-40 \\
\cline { 2 - 6 } Seedling & 3 & 8 & 2 & 8 & 6 \\
$4-20$ & 3 & 8 & 2 & 8 & 5 \\
$10-30$ & 3 & 7 & NT & 8 & 4 \\
Adult plant & 2 & 5 & NT & 5 & 3 \\
$4-20$ & & & & & \\
$10-30$ & & &
\end{tabular}

a For comparison, cultivar Avocet $S$ had infection types 8 to 9 , but it had infection types 3 and 2 when tested with PSTV-18 at seedling stage at lowand high-temperature profiles, respectively. NT, not tested (because seedlings of Eltan were highly resistant). to $60 \%$ ) compared with the susceptible parent (AvS) and susceptible winter wheat check PS279 (DS $=95$ to 100\%) (Table 2). These results indicated that Eltan had race-specific ASR and a moderate level of HTAP resistance.

Reactions of RILs to stripe rust in the greenhouse and fields. In the seedling LT tests conducted in the greenhouse, the distribution of RIL responses was skewed toward high IT (Fig. 2). In contrast, a normal to skewed distribution toward low IT was observed in the adult plant HT test in the greenhouse. In the greenhouse tests, the population medium value of IT was high when tested with both PSTv-4 (6.5) and PSTv-40 (6.7) at SLT but became much lower (3.5) when tested with PSTV-4 at HTAP. Under the field conditions, the distributions of RILs responses were skewed toward high IT and rAUDPC, with the medium value ranging from 6.3 (MT17) to 7.8 (Pullman in 2015) for IT and from 63.1 (Pullman in 2015) to 86.8 (Mount Vernon in 2016) for rAUDPC.

Based on the ANOVA results, genetic and environmental factors and their interaction had significant effects on the observed phenotypic variations $(P<0.001)$ (Table 3$). H^{2}$ values were calculated as 0.90 and 0.89 using rAUDPC and IT data, respectively. Significant correlations $(P<0.01)$ were observed among all environments (Table 4). Correlation coefficients between pairwise environments ranged from 0.25 to 0.81 for the IT data and from 0.31 to 0.80 for the rAUDPC data. Relatively low correlation coefficients were observed between the pairwise greenhouse and field environments. No significant differences were detected between winter and spring RILs with both IT and rAUDPC data (Supplementary Table $\mathrm{S} 1$ ), indicating that growth habit did not influence the responses of RILs to stripe rust.

Virulence of stripe rust samples. Races, including their virulence formulae and octal codes, for the samples collected from the fields in 2015 and 2016 were summarized in Table 5. Eleven races were identified from a total of 40 samples. PSTv-37 (70\%) was the most predominant race at Pullman in 2015, PSTv-37 (50\%) and PSTv-39 (40\%) were predominant at Mount Vernon in 2015, PSTv-37 (40\%) and PSTv-52 (30\%) were predominant at Pullman in 2016, and PSTV-75 (40\%) and PSTv-131 (30\%) were predominant at Mount Vernon in 2016. Race PSTv-37 was detected in all four environments, and PSTv-14 was detected only at Pullman in both $2015(20 \%)$ and $2016(10 \%)$. Because all of the races were virulent (IT $=7$ to 8 ) on seedlings of Eltan, the resistance observed in the fields was attributed to APR.

TABLE 2. Mean infection type (IT) and disease severity (DS) of cultivar Avocet S (AvS) and cultivar Eltan tested with Puccinia striiformis f. sp. tritici at different growth stages in various environments ${ }^{\mathrm{a}}$

\begin{tabular}{|c|c|c|c|c|c|c|}
\hline \multirow[b]{2}{*}{ Environment } & \multicolumn{2}{|c|}{ Growth stage } & \multicolumn{2}{|c|}{ AvS } & \multicolumn{2}{|c|}{ Eltan } \\
\hline & Common term & Zadaks & IT & DS & IT & DS \\
\hline $\mathrm{Pu} 15$ & Heading-flowering & $50-60$ & 8 & 95 & 7 & 50 \\
\hline $\mathrm{Pu} 16$ & Heading-flowering & $50-60$ & 8 & 100 & 4 & 50 \\
\hline MV16 & Heading-flowering & $50-60$ & 8 & 100 & 4 & 60 \\
\hline Pu17 & Heading-flowering & $50-60$ & 8 & 100 & 5 & 50 \\
\hline MV17 & Heading-flowering & $50-60$ & 8 & 100 & 4 & 30 \\
\hline $\mathrm{Pu} 18$ & Heading-flowering & $50-60$ & 8 & 100 & 6 & 50 \\
\hline PSTV-4_SLT & Two-leaf seedling & 10 & 8 & NR & 3 & NR \\
\hline PSTV-40_SLT & Two-leaf seedling & 10 & 8 & NR & 6 & NR \\
\hline PSTv-4_HTAP & Heading-flowering & $50-60$ & 8 & NR & 2 & NR \\
\hline
\end{tabular}

a The environments were field tests in Pullman 2015 (Pu15), Pullman 2016 (Pu16), Mount Vernon 2016 (MV16), Pullman 2017 (Pu17), Mount Vernon 2017 (MV17), and Pullman 2018 (Pu18) under natural infection and greenhouse tests at the seedling stage with $P$. striiformis $\mathrm{f}$. sp. tritici races PSTv-4 (PSTv-4_seedling low temperature [SLT]) and PSTV-40 (PSTv$40 \_$SLT) at the low-temperature $\left(4\right.$ to $\left.20^{\circ} \mathrm{C}\right)$ profile and the adult plant stage with $P$. striiformis f. sp. tritici race PSTv-4 at the high-temperature (10 to $30^{\circ} \mathrm{C}$ ) profile (PSTv-4_high-temperature adult plant [HTAP]). In addition to AvS, winter wheat PS279 was included in the field tests as a susceptible check and had 95 to $100 \%$ DS at the adult plant stage. NR, not recorded. 
Linkage map construction. After eliminating markers with $>10 \%$ missing data, 13,853 polymorphic SNP markers generated by $90 \mathrm{~K}$ SNP genotyping were used in the filtering process. After filtering out the markers with distorted segregation and cosegregating markers, 2,812 SNP markers were used to construct linkage groups. A total of 27 linkage groups were constructed, which spanned $2,418.46 \mathrm{cM}$. These linkage groups were assigned to corresponding chromosomes based on the chromosomal locations of SNP markers, with 16 chromosomes (1A, 1B, 1D, 2A, 2B, 3A, 3B, 4A, 4B, 4D, 5A, $5 \mathrm{~B}, 6 \mathrm{~A}, 6 \mathrm{~B}, 7 \mathrm{~B}$, and $7 \mathrm{D}$ ) each represented by a single linkage group, 4 chromosomes (3D, 5D, 6D, and 7A) each represented by two linkage groups, and chromosome 2D represented by three linkage groups. Markers in all linkage groups without cosegregating markers are given in Supplementary Table S2, and the cosegregating markers are provided in Supplementary Table S3. Figure 3 only shows the parts of linkage groups containing the mapped QTLs for stripe rust resistance.

QTL mapping for resistance at seedling stage. Three QTLs (QYrel.wgp-2BS, QYrel.wgp-4AL, and QYrel.wgp-5BS) were detected in the seedling tests with races PSTv-4 and PSTV-40 (Fig. 3 and Table 6). The major seedling resistance QTL QYrel.wgp-2BS was mapped to the centromeric region of chromosome $2 \mathrm{BS}$, and it explained 5.8 and $28.0 \%$ of the phenotypic variation observed in the tests with PSTv-4 and PSTv-40, respectively. The other major QTL,
QYrel.wgp-4AL, was mapped to the distal region of chromosome 4AL with the closest marker IWB45728, and it explained $42.0 \%$ of the phenotypic variation detected in the seedling test with PSTv-4 and $21.0 \%$ when tested with PSTv-40. QYrel.wgp-5BS in the distal region of chromosome 5BS was a minor effect QTL detected only in the test with PSTV-4, and it explained $10.0 \%$ of the observed phenotypic variation. QYrel.wgp-2BS was more effective to PSTv-40, and QYrel.wgp-4AL was more effective to PSTV-4.

QTL mapping for resistance at adult plant stage. The ASR QTLs QYrel.wgp-2BS, QYrel.wgp-4AL, and QYrel.wgp-5BS that were detected in the greenhouse seedling tests at LT with PSTv4 were also detected in the greenhouse adult plant test with the same race (Fig. 3 and Table 7). These QTLs also showed minor effects in some of the field experiments. In addition, two additional QTLs, QYrel.wgp-6AS and QYrel.wgp-7BL, were detected in some of the field experiments.

QYrel.wgp-2BS was detected with the IT data of the field experiments at Pullman in 2015, 2016, and 2017 and the greenhouse HTAP test with PSTv-4, explaining 7.2 to $15.8 \%$ of the phenotypic variation. QYrel.wgp- $4 A L$ was detected with the IT data of the Pullman 2016 and Mount Vernon 2016 field experiments and the greenhouse HTAP test, explaining 9.5 to $17.2 \%$ of the observed phenotypic variation. QYrel.wgp-5BS was detected in the field
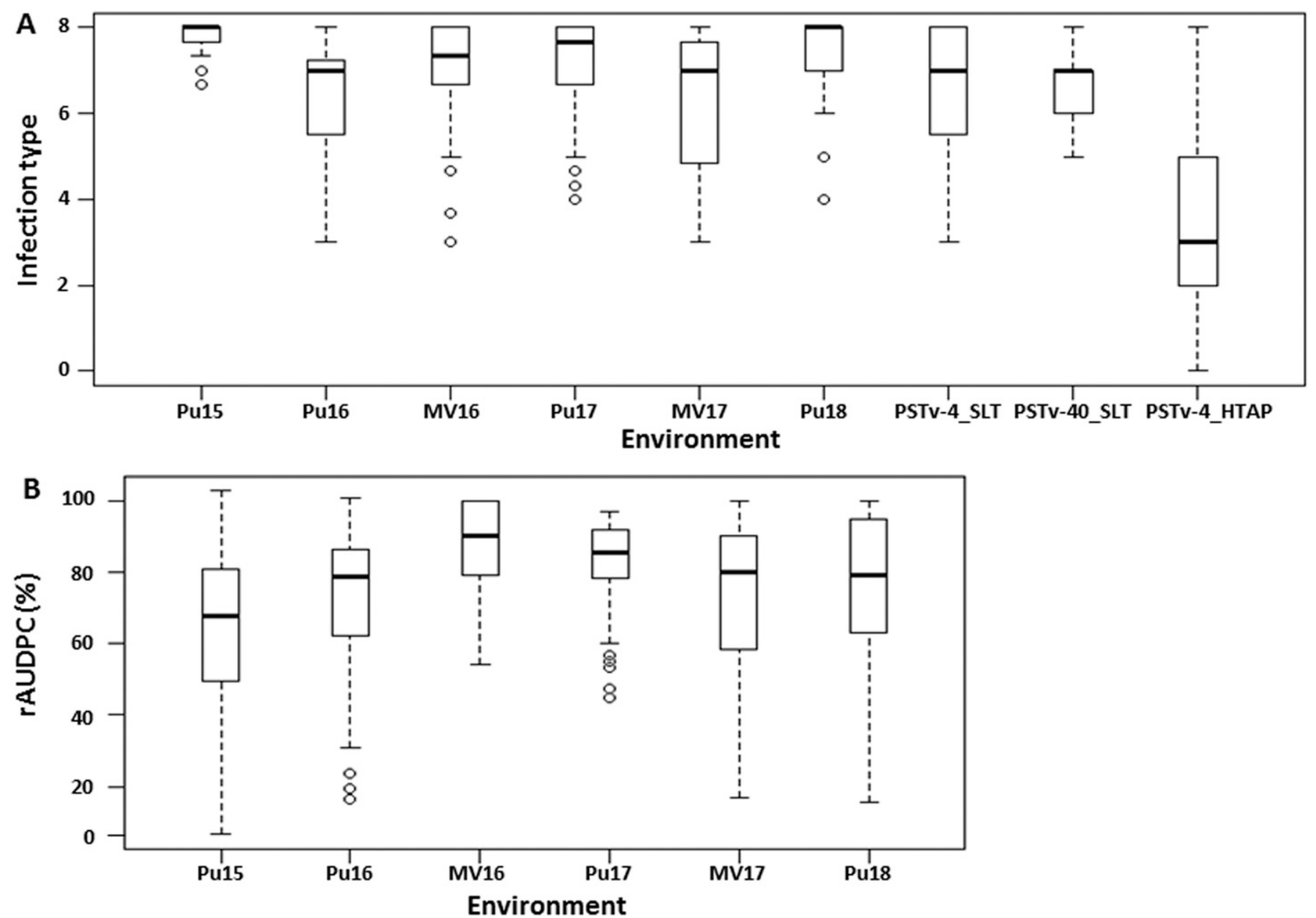

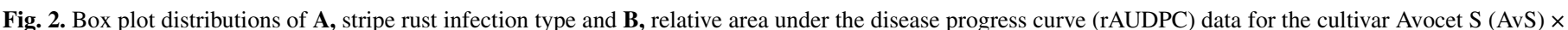

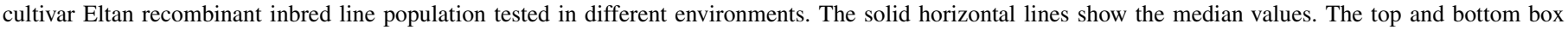

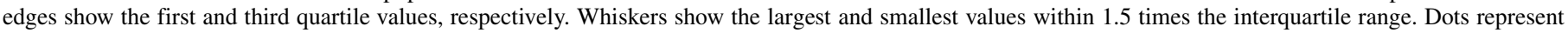

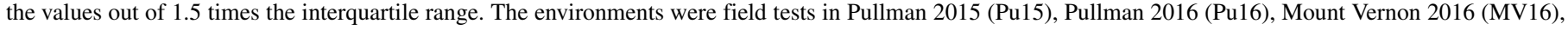

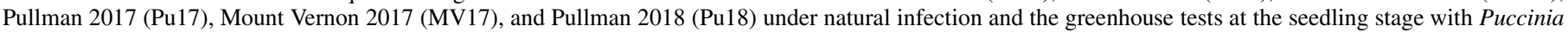

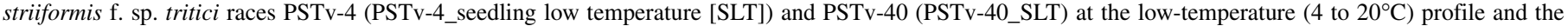
adult plant stage with PSTv-4 at the high-temperature $\left(10\right.$ to $\left.30^{\circ} \mathrm{C}\right)$ profile (PSTV-4_HTAP). 
experiments at Mount Vernon in 2016 and 2017 and Pullman in 2018 as well as in the greenhouse HTAP test, explaining 10.4 to $14.8 \%$ of the phenotypic variation. QYrel.wgp-6AS was located in the distal region of chromosome 6AS, and it was only detected in the field experiments at Pullman in 2015, 2016, and 2018, with the rAUDPC data explaining $13.5,11.6$, and $20.5 \%$ of the phenotypic variations, respectively. QYrel.wgp-7BL was mapped close to the centromere on chromosome 7BL and detected only with the rAUDPC data from the field experiments at Pullman in 2016 and 2017 and Mount Vernon 2016, with the explained percentage of observed variation ranging from 8.6 to $13.5 \%$.

In summary, relatively low QTL effects were detected in the field experiments and the HTAP test in the greenhouse. QYrel.wgp- $2 B S$ and QYrel.wgp-4AL, detected in the seedling tests, were only effective for the IT data from the field experiments. QYrel.wgp-6AS and QYrel.wgp-7BL, detected only in field tests, were only effective for the rAUDPC data. The additive effects of the five QTLs detected in the RIL population differed with IT and rAUDPC data across the different environments (Table 7).

QTL comparison. When Eltan, Luke, and AvS were genotyped by KASP markers for Qyrnap.nwafu-2BS (Wu et al. 2017), $660 \mathrm{~K}$ $A N 3,660 K-A N 21,660 K-A N 57$, and $660 K-A N 65$ produced the same haplotype $(\mathrm{C} ; \mathrm{A} ; \mathrm{T} ; \mathrm{T})$ in both Eltan and Luke and a different haplotype $(\mathrm{C} ; \mathrm{A} ; \mathrm{C} ; \mathrm{C})$ in AvS. The segregating KASP markers 660KAN57 and 660K-AN65 were mapped close to the peak of QYrel.wgp$2 B S, 1.3$ and $0.4 \mathrm{cM}$ away, respectively (Fig. 3), indicating that the QTL could be the same as Qyrnap.nwafu-2BS. STS marker Xsun104 produced a 391-bp amplicon in Eltan and a 394-bp amplicon in AvS, significantly different from the 225-bp allele diagnostic for $\operatorname{Yr} 51$, which indicates that QYrel.wgp-4AL is different from $\operatorname{Yr} 51$. For the

TABLE 3. Analysis of variance for stripe rust infection type (IT) and relative area under the disease progress curve (rAUDPC) data in the cultivar Avocet $\mathrm{S} \times$ cultivar Eltan recombinant inbred line (RIL) population tested in various environments

\begin{tabular}{|c|c|c|c|c|c|c|c|c|}
\hline \multirow[b]{2}{*}{ Source of variation } & \multicolumn{4}{|c|}{ IT } & \multicolumn{4}{|c|}{ rAUDPC } \\
\hline & $\mathrm{df}^{\mathrm{a}}$ & $\mathrm{MS}^{\mathrm{b}}$ & $F$ & $P$ value & $\mathrm{df}^{\mathrm{a}}$ & $\mathrm{MS}^{\mathrm{b}}$ & $F$ & $P$ value \\
\hline RIL & 111 & 13.16 & 39.23 & $<0.0001$ & 111 & $3,485.00$ & 40.26 & $<0.0001$ \\
\hline Environment & 4 & 124.72 & 371.87 & $<0.0001$ & 4 & $26,227.00$ & 302.94 & $<0.0001$ \\
\hline RIL $\times$ environment & 441 & 1.51 & 4.50 & $<0.0001$ & 441 & 446.00 & 5.15 & $<0.0001$ \\
\hline Replication & 2 & 0.25 & 0.75 & 0.47 & 2 & 396.00 & 4.57 & 0.01 \\
\hline Residual & 1,089 & 0.34 & & & 1,089 & 87.00 & & \\
\hline
\end{tabular}

a $\mathrm{df}=$ degree of freedom.

b $\mathrm{MS}=$ mean square.

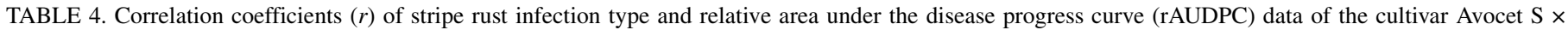
cultivar Eltan recombinant inbred line population tested in various environments ${ }^{\mathrm{a}}$

\begin{tabular}{|c|c|c|c|c|c|c|c|c|c|}
\hline \multirow[b]{2}{*}{ Environment } & \multicolumn{9}{|c|}{ Correlation coefficient ${ }^{b}$} \\
\hline & $\mathrm{Pu} 15$ & Pu16 & MV16 & Pu17 & MV17 & Pu18 & PSTV-4_SLT & PSTV-40_SLT & PSTV-4_HTAP \\
\hline $\mathrm{Pu} 16$ & $0.61(0.80)$ & 1.00 & & & & & & & \\
\hline MV16 & $0.51(0.45)$ & $0.71(0.43)$ & 1.00 & & & & & & \\
\hline $\mathrm{Pu} 17$ & $0.71(0.69)$ & $0.80(0.70)$ & $0.75(0.59)$ & 1.00 & & & & & \\
\hline MV17 & $0.55(0.62)$ & $0.78(0.73)$ & $0.78(0.46)$ & $0.81(0.70)$ & 1.00 & & & & \\
\hline Pu18 & $0.54(0.63)$ & $0.65(0.68)$ & $0.46(0.31)$ & $0.59(0.54)$ & $0.58(0.65)$ & 1.00 & & & \\
\hline PSTv-4_SLT & 0.25 & 0.58 & 0.50 & 0.45 & 0.51 & 0.43 & 1.00 & & \\
\hline PSTV-40_SLT & 0.32 & 0.54 & 0.47 & 0.50 & 0.49 & 0.35 & 0.65 & 1.00 & \\
\hline PSTV-4_HTAP & 0.31 & 0.61 & 0.53 & 0.52 & 0.58 & 0.37 & 0.53 & 0.59 & 1.00 \\
\hline
\end{tabular}

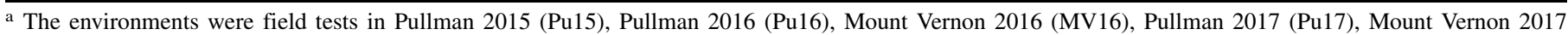
(MV17), and Pullman 2018 (Pu18) under natural infection and greenhouse tests at seedling stage with Puccinia striiformis f. sp. tritici races PSTv-4 (PSTv4_seedling low temperature [SLT]) and PSTV-40 (PSTv-40_SLT) at the low-temperature (4 to $\left.20^{\circ} \mathrm{C}\right)$ profile and the adult plant stage with PSTV-4 at the hightemperature $\left(10\right.$ to $\left.30^{\circ} \mathrm{C}\right)$ profile (PSTV-4_high-temperature adult plant [HTAP]).

b The $r$ values based on rAUDPC data are given in parentheses when data are available. All correlation coefficients were significant at $P<0.01$.

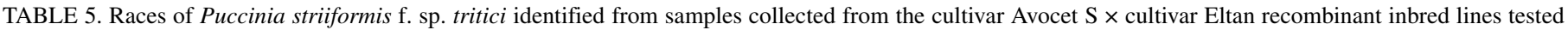
in the fields in Pullman and Mount Vernon, Washington during the 2015 and 2016 growing seasons

\begin{tabular}{|c|c|c|c|c|c|c|}
\hline Location/year & Number of isolates & Race & Octal code & Virulence formula ${ }^{a}$ & Frequency $(\%)$ & $\mathrm{IT}^{\mathrm{b}}$ on Eltan seedlings \\
\hline Pullman, 2015 & 10 & PSTv-37 & 171266 & $6,7,8,9,17,27,43,44, \operatorname{Tr} 1, \operatorname{Exp} 2$ & 70 & 8 \\
\hline Pullman, 2015 & 10 & PSTV-14 & 571267 & $1,6,7,8,9,17,27,43,44, \operatorname{Tr} 1, \operatorname{Exp} 2,76$ & 20 & 8 \\
\hline Pullman, 2015 & 10 & PSTv-47 & 571266 & $1,6,7,8,9,17,27,43,44, \operatorname{Tr} 1, \operatorname{Exp} 2$ & 10 & 8 \\
\hline Mount Vernon, 2015 & 10 & PSTV-37 & 171266 & $6,7,8,9,17,27,43,44, \operatorname{Tr} 1, \operatorname{Exp} 2$ & 50 & 8 \\
\hline Mount Vernon, 2015 & 10 & PSTV-39 & 175266 & $6,7,8,9,10,17,27,43,44, \operatorname{Tr} 1, \operatorname{Exp} 2$ & 40 & 8 \\
\hline Mount Vernon, 2015 & 10 & PSTV-283 & 171264 & $6,7,8,9,17,27,43,44, \operatorname{Tr} 1$ & 10 & 8 \\
\hline Pullman, 2016 & 10 & PSTV-37 & 171266 & $6,7,8,9,17,27,43,44, \operatorname{Tr} 1, \operatorname{Exp} 2$ & 40 & 8 \\
\hline Pullman, 2016 & 10 & PSTV-52 & 171262 & $6,7,8,9,17,27,43,44, \operatorname{Exp} 2$ & 30 & 8 \\
\hline Pullman, 2016 & 10 & PSTV-14 & 571267 & $1,6,7,8,9,17,27,43,44, \operatorname{Tr} 1, \operatorname{Exp} 2,76$ & 10 & 8 \\
\hline Pullman, 2016 & 10 & PSTv-76 & 571262 & $1,6,7,8,9,17,27,43,44, \operatorname{Exp} 2$ & 10 & 8 \\
\hline Pullman, 2016 & 10 & PSTV-127 & 551072 & $1,6,7,9,17,43,44, \mathrm{SP}, \operatorname{Exp} 2$ & 10 & 7 \\
\hline Mount Vernon, 2016 & 10 & PSTv-75 & 161062 & $6,7,8,17,43,44, \operatorname{Exp} 2$ & 40 & 8 \\
\hline Mount Vernon, 2016 & 10 & PSTV-131 & 160062 & $6,7,8,43,44, \operatorname{Exp} 2$ & 30 & 7 \\
\hline Mount Vernon, 2016 & 10 & PSTv-37 & 171266 & $6,7,8,9,17,27,43,44, \operatorname{Tr} 1, \operatorname{Exp} 2$ & 20 & 8 \\
\hline Mount Vernon, 2016 & 10 & PSTV-317 & 531235 & $1,6,8,9,17,27,44, \mathrm{SP}, \operatorname{Tr} 1,76$ & 10 & 8 \\
\hline Total & 40 & 11 & & & & \\
\hline
\end{tabular}

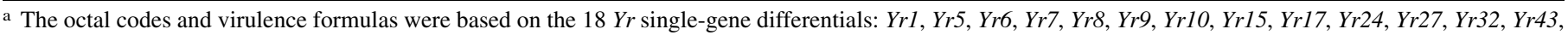
Yr44, YrSP, YrTr1, YrExp2, and Yr76 (Wan and Chen 2014; Wan et al. 2016).

b IT, infection type. 
Yr60 markers, Xwmc219 amplified a 151-bp amplicon in AvS and a 156-bp amplicon in Eltan; Xwmc313 amplified a 197-bp amplicon in AvS and a 208-bp amplicon in Eltan, and Xwmc776 amplified a 196-bp amplicon in AvS but no amplicons in Eltan. All three markers were mapped in the QYrel.wgp-4AL region (Fig. 3), but Xwmc776, cosegregating with $\operatorname{Yr} 60$, failed to amplify any amplicon in Eltan. These results may suggest that QYrel.wgp-4AL and Yr60 could be different alleles or closely linked genes. SSR marker Xgwm234 produced a 239-bp amplicon in Eltan and a 249-bp amplicon in AvS, and the marker locus was mapped $8.6 \mathrm{cM}$ distal of the QYrel.wgp$5 B S$ (Fig. 3). Because the SSR marker Xcfb309 produced a 370-bp amplicon in both Eltan and AvS, the marker locus could not be mapped in the AvS $\times$ Eltan population. These results indicated that QYrel.wgp-5BS was unlikely to be $\mathrm{Yr} 47$.

\section{DISCUSSION}

Eltan, the most widely grown winter wheat cultivar in the U.S. PNW region, has exhibited a range of resistance levels in the past 30 years. The variation in resistance level can be attributed to the changes of predominant races circumventing ASR and the effects of environmental conditions and disease pressure on HTAP resistance in Eltan. In this study, five QTLs were identified for resistance to stripe rust in Eltan, with two major QTLs and one minor QTL for ASR and two additional QTLs for HTAP resistance detected in the field experiments. Stripe rust samples collected from the RILs in the field experiments of 2015 and 2016 were identified as races virulent on the seedlings of Eltan. Races avirulent to seedlings of Eltan, such as PSTv-4 and PSTv-40 that were predominant in the PNW region
2BS

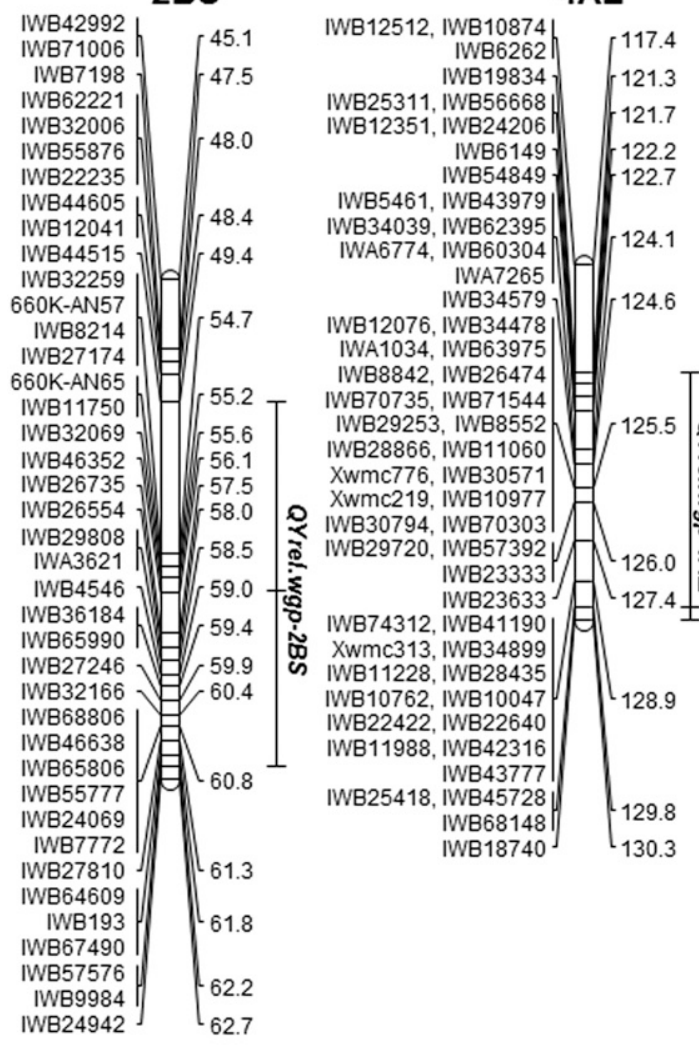

5BS
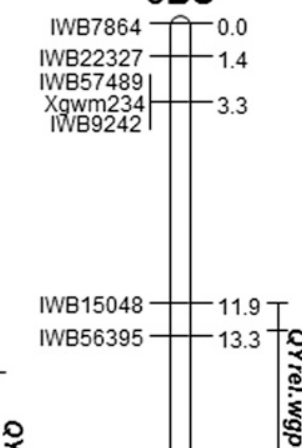
IWA435 $h / 21.0$ WB10337) 23.0 IWB8553
IWB48848 25.4 IWB14983
IWB12270
IWB6661
IWB7252 IWB58311 N 28.8 IWB62348 $\mathrm{H}$ (31.2 IWB36148 IWB34551 33.2 IWB9125 ${ }^{33}$ IWB24716 IWB31059 $/ 33.7$ $\left.\begin{array}{l}\text { IWB5977 } \\ \text { IWB58506 }\end{array}\right]$

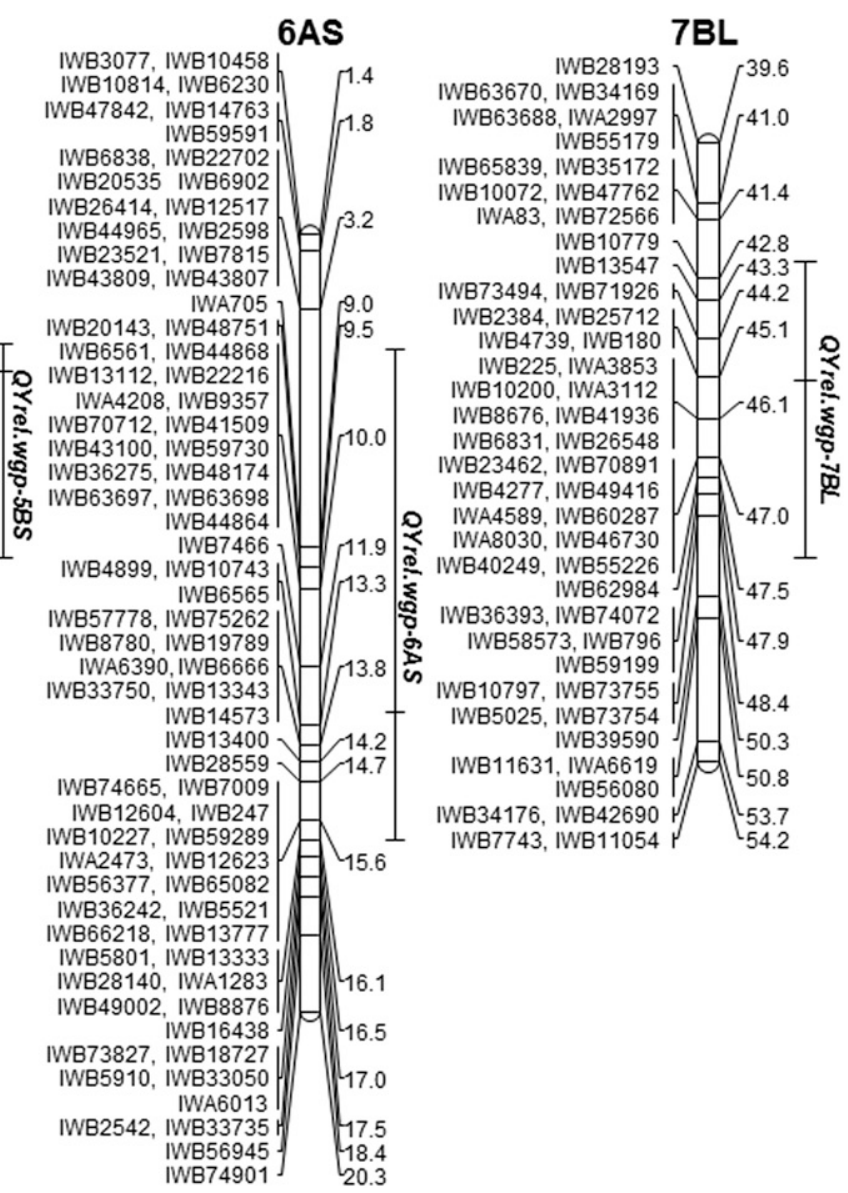

Fig. 3. Linkage groups for quantitative trait loci (QTL) QYrel.wgp-2BS, QYrel.wgp-4AL, QYrel.wgp-5BS, QYrel.wgp-6AS, and QYrel.wgp-7BL for resistance to stripe rust mapped in the cultivar Avocet $\mathrm{S}(\mathrm{AvS}) \times$ cultivar Eltan recombination inbred population. The map shows the selected portions of the linkage groups containing the QTL; the markers for the entire chromosomes of the five linkages and the remaining 16 chromosomes are not shown.

TABLE 6. Quantitative trait loci (QTLs) for resistance to races PSTv-4 and PSTv-40 of Puccinia striiformis $\mathrm{f}$. sp. tritici detected in the cultivar Avocet S $\times$ cultivar Eltan recombinant inbred line population tested at the seedling stage in the greenhouse under the low-temperature $\left(4\right.$ to $\left.20^{\circ} \mathrm{C}\right)$ profile ${ }^{\mathrm{a}}$

\begin{tabular}{|c|c|c|c|c|c|}
\hline QTL and race & Closest marker & Peak position $(\mathrm{cM})$ & LOD & $R^{2 \mathrm{~b}}(\%)$ & $\mathrm{AE}^{\mathrm{c}}$ \\
\hline \multicolumn{6}{|l|}{ QYrel.wgp- $2 B S$} \\
\hline PSTV-4 & IWB26735 & 57.55 & 3.42 & 5.78 & -0.35 \\
\hline PSTv-40 & IWB32259 & 54.41 & 12.72 & 27.98 & -0.41 \\
\hline PSTV-4 & IWB45728 & 129.84 & 17.72 & 41.98 & -0.87 \\
\hline PSTV-40 & $I W B 45728$ & 129.84 & 8.70 & 21.02 & -0.35 \\
\hline \multicolumn{6}{|l|}{ QYrel.wgp-5BS } \\
\hline PSTV-4 & IWB56395 & 13.35 & 4.58 & 9.97 & -0.51 \\
\hline
\end{tabular}

a AE, additive effect; LOD, logarithm (base 10) of odds.

${ }^{\mathrm{b}} R^{2}$ value was measured as the percentage of the total observed phenotypic variation explained, indicating the effect of the QTL.

c A negative value indicates that the resistance allele is from Eltan. 
from 2000 to 2009 and PSTv-18 that was predominant in the $1990 \mathrm{~s}$ (Liu et al. 2017; Wan and Chen 2012, 2014), were not detected from the samples collected from the fields for RIL phenotyping. Similarly, the races avirulent to Eltan at seedling stage were detected in very low frequencies in the whole PNW region, but PSTv-37 virulent to seedling Eltan was the predominant race in the region from 2015 to 2018 (A. M. Wan, M. N. Wang, and X. M. Chen, unpublished data). Thus, reduction of resistance may have been caused by the appearance and frequency increase of virulent races circumventing ASR. The race-specific ASR QTLs (QYrel.wgp2BS, QYrel.wgp-4AL, and QYrel.wgp-5BS), which were detected in the greenhouse tests of both seedling and adult plant stages with avirulent race PSTV-4, still showed some residual effects in the fields where virulent races, like PSTv-37, were predominant. In addition, two minor QTLs (QYrel.wgp-6AS and QYrel.wgp-7BL) conferring nonrace-specific HTAP resistance in Eltan were detected in the fields. The combination of residual race-specific resistance and HTAP resistance has reduced potential yield losses of Eltan by $>50 \%$ (Chen 2014; Chen et al. 2015, 2016, 2017, 2018).

QYrel.wgp-2BS is an ASR QTL on chromosome 2BS close to the centromere, and it is more effective to race PSTv-40 than to PSTv-4. ASR genes $Y r 27$ (McDonald et al. 2004) and Yr41 (Luo et al. 2005) were mapped close to QYrel.wgp-2BS. Yr27 is present in many International Wheat and Maize Improvement Center wheat lines and widely deployed in cultivars in India, Ethiopia, Iran, Pakistan, and Syria. Yr41 was identified in Chinese wheat AIM6 and is present in other Chinese wheat lines. Based on the pedigree of Eltan, these two genes are not possible in Eltan, making QYrel.wgp-2BS likely different from $Y r 27$ and $Y r 41$. Winter wheat Luke is in the pedigree of Eltan, and two QTLs on 2BS QYrlu.cau-2BS1 and QYrlu.cau-2BS2 were identified in Luke, with QYrlu.cau- $2 B S 2$ mapped close to the centromere (Guo et al. 2008). It is very likely that QYrel.wgp-2BS is the same QTL as QYrlu.cau-2BS2 in Luke. Qyrnap.nwafu-2BS in wheat variety Napo 63 (Wu et al. 2017) was also mapped close to QYrel.wgp-2BS. Four KASP markers developed to detect Qyrnap.nwafu-2BS were used to genotype AvS, Eltan, and Luke. Eltan and Luke had the same haplotype of the four KASP markers, confirming that Eltan inherited the haplotype from Luke based on Eltan's pedigree (Peterson et al. 1991). However, our haplotype $(\mathrm{C} ; \mathrm{A} ; \mathrm{T} ; \mathrm{T})$ of Luke and Eltan was different from their haplotype $(\mathrm{A} ; \mathrm{G} ; \mathrm{T} ; \mathrm{T})$ of Luke and Napo 63 (the parent carrying Qyrnap.nwafu-2BS) (Wu et al. 2017). The difference might be caused by different Luke plants used in the different experiments. Because Napo 63 was not available in our study, we could not confirm its haplotype, although AvS had the same haplotype in both studies. Because two KASP markers (660K-AN57 and 660K-AN65) were mapped so close to the peak of QYrel.wgp-2BS (only 1.3 and $0.4 \mathrm{cM}$ in distance, respectively), it is likely the same as Qyrnap.nwafu-2BS. In a 2018 study, QYr.ucw-2BS was identified in the region of QYrel.wgp-2BS from an Argentinean wheat cultivar (Cobo et al. 2018). RILs carrying only $Q Y r . u c w-2 B S(I T=4)$ were more resistant to PSTv-4 than QYrel.wgp-2BS (IT = 6 to 7), and therefore, these two QTL should be different.

QYrel.wgp-4AL was the other major ASR QTL in Eltan mapped to the distal region of 4AL. One minor QTL in the centromeric region of 4AL was also detected in Eltan in one field environment (Pullman 2016). Because the minor QTL did not reach threshold $(\mathrm{LOD}=3.02)$, it was not reported in this study. QYrel.wak-4A, mapped to the centromeric region of $4 \mathrm{AL}$, was detected in the Finch $\times$ Eltan RIL population in fields (Klarquist et al. 2016). QYrel.wak$4 A$ should be the same minor QTL as detected in this study, whereas QYrel.wgp-4AL is a major effect ASR QTL, different from QYrel.wak-4A. Yr51 and Yr60 were also mapped close to QYrel.wgp-4AL (Herrera-Foessel et al. 2015; Randhawa et al. 2014). Because Eltan does not have the diagnostic 225-bp marker of Xsun104 for Yr51, QYrel.wgp-4AL should be different from Yr51. Although Xwmc219, Xwmc313, and Xwmc776 for Yr60 were mapped to the region of QYrel.wgp-4AL, Yr60 cosegregating marker $X w m c 776$ failed to amplify any products in Eltan, making QYrel.wgp-4AL different from Yr60. Therefore, QYrel.wgp-4AL is a novel gene for ASR to stripe rust.

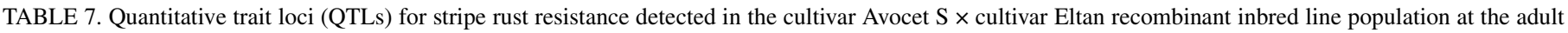

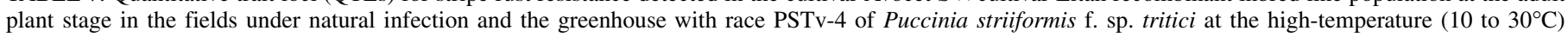
profile $^{\mathrm{a}}$

\begin{tabular}{|c|c|c|c|c|c|}
\hline QTL and experiment data & Closest marker & Peak position $(\mathrm{cM})$ & LOD & $R^{2 \mathrm{~b}}(\%)$ & $\mathrm{AE}^{\mathrm{c}}$ \\
\hline \multicolumn{6}{|l|}{ QYrel.wgp-2BS } \\
\hline Pu15-IT & $I W B 26735$ & 57.55 & 3.92 & 11.38 & -0.11 \\
\hline Pu16-IT & $I W B 26735$ & 57.55 & 6.54 & 15.84 & -0.58 \\
\hline Pu17-IT & IWB32259 & 54.41 & 3.21 & 7.63 & -0.29 \\
\hline PSTv-4_HTAP & $I W B 32259$ & 54.41 & 3.60 & 7.21 & -0.54 \\
\hline \multicolumn{6}{|l|}{ QYrel.wgp- $4 A L$} \\
\hline Pu16-IT & $I W B 45728$ & 129.84 & 4.01 & 9.52 & -0.40 \\
\hline MV16-IT & $I W B 45728$ & 129.84 & 4.29 & 10.85 & -0.35 \\
\hline PSTV-4_HTAP & IWB45728 & 129.84 & 7.83 & 17.18 & -0.81 \\
\hline \multicolumn{6}{|l|}{ QYrel.wgp-5BS } \\
\hline MV16-IT & IWB56395 & 12.94 & 3.84 & 10.38 & -0.36 \\
\hline MV17-IT & IWB56395 & 12.94 & 5.21 & 13.49 & -0.65 \\
\hline MV17-rAUDPC & IWB56395 & 12.94 & 6.51 & 14.75 & -8.96 \\
\hline $\mathrm{Pu} 18-\mathrm{IT}$ & IWB56395 & 12.94 & 4.99 & 12.01 & -0.43 \\
\hline PSTv-4_HTAP & IWB56395 & 13.35 & 5.10 & 10.59 & -0.67 \\
\hline \multicolumn{6}{|l|}{ QYrel.wgp-6AS } \\
\hline Pu15-rAUDPC & IWB6565 & 13.30 & 5.27 & 13.54 & -8.62 \\
\hline Pu16-rAUDPC & IWB6666 & 13.76 & 5.42 & 11.56 & -6.64 \\
\hline Pu18-rAUDPC & $I W B 7466$ & 11.89 & 8.45 & 20.48 & -10.50 \\
\hline \multicolumn{6}{|l|}{ QYrel.wgp-7BL } \\
\hline Pu16-rAUDPC & IWB4739 & 45.15 & 5.05 & 10.65 & -6.49 \\
\hline MV16-rAUDPC & $I W B 4739$ & 45.15 & 4.20 & 8.62 & -6.39 \\
\hline Pu17-rAUDPC & IWB4739 & 45.15 & 5.21 & 13.53 & -4.46 \\
\hline
\end{tabular}

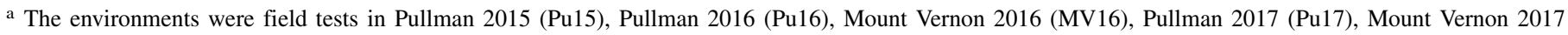
(MV17), and Pullman 2018 (Pu18) under natural infection and greenhouse test at adult plant stage with race PSTV-4 at the high-temperature (10 to $30^{\circ} \mathrm{C}$ ) profile (PSTV-4_high-temperature adult plant [HTAP]). The datasets were infection type (IT) and relative area under the disease progress curve (rAUDPC). AE, additive effect; LOD, logarithm (base 10) of odds.

${ }^{\mathrm{b}} R^{2}$ value was measured as the percentage of the total observed phenotypic variation explained, indicating the effect of the QTL.

c A negative value indicates that the resistance allele is from Eltan. 
QYrel.wgp-5BS was identified as a minor effect ASR QTL, effective against race PSTV-4 and in some field experiments. Only ASR gene Yr47 (Bansal et al. 2011; Qureshi et al. 2017) was mapped close to QYrel.wgp-5BS. Yr47 is tightly linked with leaf rust resistance gene $L r 52$, whereas Eltan is susceptible to leaf rust (Peterson et al. 1991). In addition, both Xgwm234 and Xcfb309 flanking $Y r 47$ amplified alleles in Eltan different from those in the Yr47-carrying variety. This evidence indicates that QYrel.wgp-5BS is different from $\mathrm{Yr} 47$.

QYrel.wgp-6AS was only detected in some field experiments with the rAUDPC data. On the short arm of 6A, Yr38 (Marais et al. 2006), Yr42 (Marais et al. 2009), QYrex.wgp-6AS (Lin and Chen 2009), and QYr.uga-6AS (Hao et al. 2011) were located closely to QYrel.wgp-6AS. Yr38 and Yr42 were transferred from wild wheat relatives. QYrex.wgp-6AS and QYr.uga-6AS are HTAP resistance QTLs detected in spring wheat cultivar Express and winter wheat cultivar Pioneer 26R61, respectively. The relationships of $Q Y r$ el.wgp-6AS with these two HTAP resistance QTLs need additional studies. Similar to QYrel.wgp-6AS, QYrel.wgp-7BL was also detected only in some field tests with rAUDPC data. A major HTAP resistance gene $Y r 39$ was mapped in the same region as QYrel.wgp-7BL (Lin and Chen 2007). QYrel.wgp-7BL might be the same as Yr39, but additional studies are needed to determine their relationship.

In summary, two major effect QTLs and one minor effect QTL for ASR and two QTLs for HTAP resistance were identified in Eltan. All QTLs were detected in multiple environments, and the relationships of the QTLs with previously reported genes or QTLs need additional confirmation. Although Eltan has five QTLs that provide a high level of resistance when avirulent races are predominant, the cultivar can have significant yield losses when virulent races are in a higher proportion. However, the partially defeated race-specific ASR can still make some contributions to residual resistance, which together with the low to moderate level of HTAP resistance, has prevented Eltan from becoming completely susceptible. Nevertheless, new cultivars should have a much higher level of resistance than Eltan. Because Eltan is a major elite cultivar in the PNW, it can be used in crosses with other resistant germplasm for developing new cultivars with durable, high-level resistance to stripe rust by combining its QTLs with other genes for effective ASR and HTAP resistance as well as its other desirable agronomic traits. The molecular markers identified in this study should be useful for marker-assisted selection of the stripe rust resistance QTLs from Eltan.

\section{ACKNOWLEDGMENTS}

We thank S. Chao for $90 \mathrm{~K}$ single-nucleotide polymorphism genotyping and K. Evans and J. Sprott for field preparation and weed control. The China Scholarship Council scholarship to L. Liu is highly appreciated.

\section{LITERATURE CITED}

Bansal, U. K., Forrest, K. L., Hayden, M. J., Miah, H., Singh, D., and Bariana, H. S. 2011. Characterisation of a new stripe rust resistance gene Yr47 and its genetic association with the leaf rust resistance gene Lr52. Theor. Appl. Genet. 122:1461-1466.

Broman, K. W., Wu, H., Sen, Ś., and Churchill, G. A. 2003. R/qtl: QTL mapping in experimental crosses. Bioinformatics 19:889-890.

Carleton, M. A. 1915. A serious new wheat rust in this country. Science 42:58-59.

Chen, X. M. 2005. Epidemiology and control of stripe rust [Puccinia striiformis f. sp. tritici] on wheat. Can. J. Plant Pathol. 27:314-337.

Chen, X. M. 2007. Challenges and solutions for stripe rust control in the United States. Aust. J. Agric. Res. 58:648-655.

Chen, X. M. 2013. High-temperature adult-plant resistance, key for sustainable control of stripe rust. Am. J. Plant Sci. 4:608-627.

Chen, X. M. 2014. Integration of cultivar resistance and fungicide application for control of wheat stripe rust. Can. J. Plant Pathol. 36:311-326.

Chen, X. M., Evans, C. K., and Liu, Y. M. 2016. Responses of winter wheat cultivars to fungicide application for control of stripe rust in 2015. Plant Dis. Manage. Rep. 10:C023.
Chen, X. M., Evans, C. K., Liu, Y. M., and Heath, M. 2015. Effects of fungicide application on control of stripe rust on winter wheat cultivars in 2014. Plant Dis. Manage. Rep. 9:CF017.

Chen, X. M., Evans, C. K., Sprott, J., and Liu, Y. M. 2017. Evaluation of winter wheat cultivars to fungicide application for control of stripe rust in 2016. Plant Dis. Manage. Rep. 11:CF015.

Chen, X. M., Evans, C. K., Sprott, J., and Liu, Y. M. 2018. Evaluation of Pacific Northwest winter wheat cultivars to fungicide application for control of stripe rust in 2017. Plant Dis. Manage. Rep. 12:CF075.

Chen, X. M., and Line, R. F. 1992. Inheritance of stripe rust resistance in wheat cultivars used to differentiate races of Puccinia striiformis in North America. Phytopathology 82:633-637.

Chen, X. M., and Line, R. F. 1995. Gene action in wheat cultivars for durable, high-temperature, adult-plant resistance and interactions with racespecific, seedling resistance to Puccinia striiformis. Phytopathology 85: 567-572.

Chen, X. M., Moore, M., Milus, E. A., Long, D. L., Line, R. F., Marshall, D., and Jackson, L. 2002. Wheat stripe rust epidemics and races of Puccinia striiformis f. sp. tritici in the United States in 2000. Plant Dis. 86:39-46.

Chen, X. M., Penman, L., Wan, A. M., and Cheng, P. 2010. Virulence races of Puccinia striiformis f. sp. tritici in 2006 and 2007 and development of wheat stripe rust and distributions, dynamics, and evolutionary relationships of races from 2000 to 2007 in the United States. Can. J. Plant Pathol. 32: 315-333.

Churchill, G., and Doerge, R. W. 1994. Empirical threshold values for quantitative trait mapping. Genetics 138:963-971.

Clarke, J. D. 2002. Cetyltrimethyl ammonium bromide (CTAB) DNA miniprep for plant DNA isolation. Page 165 in: Arabidopsis: A Laboratory Manual, D. Weigel and J. Glazebrook, eds. CSHL Press, Cold Spring Harbor, NY.

Cobo, N., Pflüger, L., Chen, X., and Dubcovsky, J. 2018. Mapping QTL for resistance to new virulent races of wheat stripe rust from two Argentinean wheat cultivars. Crop Sci. 58:2470-2483.

Fu, D., Uauy, C., Distelfeld, A., Blechl, A., Epstein, L., Chen, X., Sela, H., Fahima, T., and Dubcovsky, J. 2009. A kinase-START gene confers temperature-dependent resistance to wheat stripe rust. Science 323: 1357-1360.

Gou, J., Li, K., Wu, K., Wang, X., Lin, H., Cantu, D., Uauy, C., Dobon-Alonso, A., Midorikawa, T., Inoue, K., Sánchez, J., Fu, D., Blechl, A., Wallington, E., Fahima, T., Meeta, M., Epstein, L., and Dubcovsky, J. 2015. Wheat stripe rust resistance protein WKS1 reduces the ability of the thylakoid-associated ascorbate peroxidase to detoxify reactive oxygen species. Plant Cell 27:1755-1770.

Guo, Q., Zhang, Z. J., Xu, Y. B., Li, G. H., Feng, J., and Zhou, Y. 2008. Quantitative trait loci for high-temperature adult-plant and slow-rusting resistance to Puccinia striiformis f. sp. tritici in wheat cultivars. Phytopathology 98:803-809.

Hao, Y. F., Chen, Z. B., Wang, Y. Y., Bland, D., Buck, J., Brown-Guedira, G., and Johnson, J. 2011. Characterization of a major QTL for adult plant resistance to stripe rust in US soft red winter wheat. Theor. Appl. Genet. 123:1401-1411.

Herrera-Foessel, S. A., Singh, R. P., Lan, C. X., Huerta-Epino, J., Calvo-Salazar, V., Bansal, U. K., Bariana, H. S., and Lagudah, E. S. 2015. Yr60, a gene conferring moderate resistance to stripe rust in wheat. Plant Dis. 99:508-511.

Hou, L., Chen, X. M., Wang, M. N., See, D. R., Chao, S. M., Bulli, P., and Jing, J. X. 2015. Mapping a large number of QTL for durable resistance to stripe rust in winter wheat Druchamp using SSR and SNP markers. PLoS One 10:e0126794.

Hovmøller, M. S., and Justesen, A. F. 2007. Rates of evolution of avirulence phenotypes and DNA markers in a northwest European population of Puccinia striiformis f. sp. tritici. Mol. Ecol. 16:4637-4647.

Klarquist, E. F., Chen, X. M., and Carter, A. H. 2016. Novel QTL for stripe rust resistance on chromosomes $4 \mathrm{~A}$ and $6 \mathrm{~B}$ in soft white winter wheat cultivars. Agronomy (Basel) 6:4.

Krattinger, S. G., Lagudah, E. S., Spielmeyer, W., Singh, R. P., Huerta-Espino, J., McFadden, M., Bossolini, E., Selter, L. L., and Keller, B. 2009. A putative $\mathrm{ABC}$ transporter confers durable resistance to multiple fungal pathogens in wheat. Science 323:1360-1363.

Lei, Y., Wang, M. N., Wan, A. M., Xia, C. J., See, D. R., Zhang, M., and Chen, X. M. 2017. Virulence and molecular characterization of experimental isolates of the stripe rust pathogen (Puccinia striiformis) indicate somatic recombination. Phytopathology 107:329-344.

Lin, F., and Chen, X. M. 2007. Genetics and molecular mapping of genes for race- specific and all-stage resistance and non-specific high-temperature adult-plant resistance to stripe rust in spring wheat cultivar Alpowa. Theor. Appl. Genet. 114:1277-1287. 
Lin, F., and Chen, X. M. 2009. Quantitative trait loci for non-race-specific, high-temperature adult-plant resistance to stripe rust in wheat cultivar Express. Theor. Appl. Genet. 118:631-642.

Line, R. F., and Qayoum, A. 1992. Virulence aggressiveness, evolution, and distribution of races of Puccinia striiformis (the cause of stripe rust of wheat) in North America, 1968-87. U.S. Department of Agriculture Technical Bulletin No. 1788, National Technical Information Service, Springfield, VA.

Liu, L., Wang, M. N., Feng, J. Y., See, D. R., Chao, S. M., and Chen, X. M. 2018. Combination of all-stage and high-temperature adult-plant resistance QTL confers high-level, durable resistance to stripe rust in winter wheat cultivar Madsen. Theor. Appl. Genet. 131:1835-1849.

Liu, T. L., Wan, A. M., Liu, D. C., and Chen, X. M. 2017. Changes of races and virulence genes of Puccinia striiformis $\mathrm{f}$. sp. tritici, the wheat stripe rust pathogen, in the United States from 1968 to 2009. Plant Dis. 101:1522-1532.

Lu, Y., Wang, M. N., Chen, X. M., See, D. R., Chao, S. M., and Jing, J. X. 2014. Mapping of Yr62 and a small-effect QTL for high-temperature adultplant resistance to stripe rust in spring wheat PI 192252. Theor. Appl. Genet. 127:1449-1459.

Luo, P. G., Ren, Z. L., Zhang, H. Q., and Zhang, H. Y. 2005. Identification, chromosome location, and diagnostic markers for a new gene $(\mathrm{YrCN19})$ for resistance to wheat stripe rust. Phytopathology 95:1266-1270.

Marais, F., Marais, A., McCallum, B., and Pretorius, Z. 2009. Transfer of leaf rust and stripe rust resistance genes Lr62 and Yr42 from Aegilops neglecta Req. ex Bertol. to common wheat. Crop Sci. 49:871-879.

Marais, G. F., McCallum, B., and Marais, A. S. 2006. Leaf rust and stripe rust resistance genes derived from Triticum sharonense. Euphytica 149:373-380.

McDonald, D., McIntosh, R. A., Wellings, C. R., Singh, R. P., and Nelson, J. C. 2004. Cytogenetical studies in wheat XIX. Location and linkage studies on gene $\operatorname{Yr} 27$ for resistance to stripe (yellow) rust. Euphytica 136: 239-248.

Moore, J. W., Herrera-Foessel, S., Lan, C., Schnippenkoetter, W., Ayliffe, M., Huerta-Espino, J., Lillemo, M., Viccars, L., Milne, R., Periyannan, S., Kong, X., Spielmeyer, W., Talbot, M., Bariana, H., Patrick, J. W., Dodds, P., Singh, R., and Lagudah, E. 2015. A recently evolved hexose transporter variant confers resistance to multiple pathogens in wheat. Nat. Genet. 47: 1494-1498.

Peterson, C. J., Allan, R. E., Rubenthaler, G. L., and Line, R. F. 1991. Registration of 'Eltan' wheat. Crop Sci. 31:1704.
Qureshi, N., Bariana, H., Forrest, K., Hayden, M., Keller, B., Wicker, T., Faris, J., Salina, E., and Bansal, U. 2017. Fine mapping of the chromosome 5B region carrying closely linked rust resistance genes $\mathrm{Yr} 47$ and $\mathrm{Lr} 52$ in wheat. Theor. Appl. Genet. 130:495-504.

Randhawa, M., Bansal, U., Valárik, M., Klocová, B., Doleźel, J., and Bariana, H. 2014. Molecular mapping of stripe rust resistance gene Yr51 in chromosome 4AL of wheat. Theor. Appl. Genet. 127:317-324.

Sharma-Poudyal, D., and Chen, X. M. 2011. Models for predicting potential yield loss of wheat caused by stripe rust in the U. S. Pacific Northwest. Phytopathology 101:544-554.

Van Ooijen, J. W. 2006. JoinMap 4, Software for the Calculation of Genetic Linkage Maps in Experimental Populations. Kyazma B.V., Wageningen, The Netherlands.

Voorrips, R. E. 2002. MapChart: Software for the graphical presentation of linkage maps and QTLs. J. Hered. 93:77-78.

Wan, A. M., and Chen, X. M. 2012. Virulence, frequency, and distribution of races of Puccinia striiformis f. sp. tritici and $P$. striiformis f. sp. hordei identified in the United States in 2008 and 2009. Plant Dis. 96:67-74.

Wan, A. M., and Chen, X. M. 2014. Virulence characterization of Puccinia striiformis $\mathrm{f}$. sp. tritici using a new set of $\mathrm{Yr}$ single-gene line differentials in the United States in 2010. Plant Dis. 98:1534-1542.

Wan, A. M., Chen, X. M., and Yuen, J. 2016. Races of Puccinia striiformis f. sp. tritici in the United States in 2011 and 2012 and comparison with races in 2010. Plant Dis. 100:966-975.

Wan, A. M., Zhao, Z. H., Chen, X. M., He, Z. H., Jin, S. L., Jia, Q. Z., Yao, G., Yang, J. X., Wang, B. T., Li, G. B., Bi, Y. Q., and Yuan, Z. Y. 2004. Wheat stripe rust epidemic and virulence of Puccinia striiformis f. sp. tritici in China in 2002. Plant Dis. 88:896-904.

Wang, S., Wong, D., Forrest, K., Allen, A., Chao, S., Huang, B. E., Maccaferri, M., Salvi, S., Milner, S. G., and Cattivelli, L. 2014. Characterization of polyploid wheat genomic diversity using a high-density 90,000 single nucleotide polymorphism array. Plant Biotechnol. J. 12:787-796.

Wellings, C. R. 2011. Global status of stripe rust: A review of historical and current threats. Euphytica 179:129-141.

Wu, J., Wang, Q., Liu, S., Huang, S., Mu, J., Zeng, Q., Huang, L., Han, D., and Kang, Z. 2017. Saturation mapping of a major effect QTL for stripe rust resistance on wheat chromosome 2B in cultivar Napo 63 using SNP genotyping arrays. Front. Plant Sci. 8:653.

Zadoks, J. C., Chang, T. T., and Konzak, C. F. 1974. A decimal code for the growth stages of cereals. Weed Res. 14:415-421. 